\title{
O uso do padlet na aprendizagem da Língua Inglesa: um relato de experiências
}

\author{
Luzia Alves de Carvalho ${ }^{1,}$ Ana Paula de Castro ${ }^{1}$, Shayane Ferreira Dos Santos ${ }^{1}$, \\ Anna Luisa do Nascimento Ferreira ${ }^{1}$, Jéssica Ribeiro ${ }^{1}$ \\ ${ }^{1}$ Centro Educacional Nossa Senhora Auxiliadora (CENSA) \\ Campos dos Goytacazes- RJ - Brazil
}

\begin{abstract}
RESUMO
As Tecnologias Digitais da Informação e Comunicação (TDIC) têm um papel fundamental para o modelo de ensino ativo. Este artigo pretende investigar como a habilidade escrita em língua inglesa pode ser aprimorada com a colaboração entre os alunos, por meio da ferramenta on-line interativa Padlet. A metodologia baseia-se numa abordagem qualitativa e os instrumentos de coletas de dados foram observação, questionários e respostas das atividades. A análise dos dados demonstrou que as atividades de língua inglesa realizadas no Padlet, com apoio das TDIC, tornaram as propostas mais interessantes e que os alunos conseguem aprender ao observar as contribuições dos colegas, considerando estas um fator de auxílio à criatividade, à escrita e à aprendizagem do vocabulário.
\end{abstract}

\begin{abstract}
Digital Information and Communication Technologies (TDIC) have a fundamental role for the active teaching model. This article aimed to investigate how learning a written skill in English can be improved with collaboration among students and through an interactive online tool called Padlet. A qualitative approach was adopted and the data collection instruments were observation, questionnaires and responses to the proposed. The analysis of the data showed that the activities in English carried out on Padlet, with the support of TDIC, made the proposals more interesting and the students were able to learn by observing the contributions of their colleagues, considering this a factor of support to creativity in writing and learning new vocabulary.
\end{abstract}

\section{INTRODUÇÃO}

A tecnologia tem se tornado onipresente em nosso cotidiano, fazendo-se necessária em todos os setores de nossa vida, inclusive na educação. Cada vez mais, recursos tecnológicos são inseridos no contexto educacional com cunho pedagógico e o Padlet é um deles. As Tecnologias Digitais da Informação e Comunicação (TDIC) desempenham um papel fundamental na transição do modelo tradicional de ensino para 
o modelo de ensino mais ativo, centrado no aluno e buscando que este seja o ator principal no processo de aprendizagem (RASHID; YUNUS; WAHI, 2019).

Desta forma, foram planejadas e executadas quatro práticas pedagógicas para introduzir novos conteúdos gramaticais nas aulas de Língua Inglesa, envolvendo, sobretudo, a habilidade escrita. Assim, este artigo pretende, além de relatar tais práticas, investigar como a habilidade escrita em língua inglesa pode ser aprimorada com a colaboração entre os alunos, por meio da ferramenta on-line interativa Padlet.

O Padlet (https://www.padlet.com) é um aplicativo gratuito baseado na Web, que fornece um "mural", em que ao usuário é permitido postar palavras, fotos, links e vídeos, e que pode ser visualizado por qualquer pessoa com o link ou endereço do mural específico (RASHID; YUNUS; WAHI, 2019). Além disso, ele permite visualizar uma variedade de respostas que promovem a oportunidade de aprendizado e autoavaliação, individual e coletivamente, tendo em vista o fato dos alunos terem acesso imediato a um amplo espectro de respostas de seus colegas de classe (RASHID; YUNUS; WAHI, 2019). Assim, este recurso mostra-se de grande potencial, especialmente neste momento de afastamento social e aulas remotas na pandemia.

O modelo de ensino mais tradicional faz do professor o protagonista do processo de aprendizagem, em práticas centradas na transmissão de conteúdo ao aluno, de forma sistemática e organizada, em que o conteúdo, por muitas vezes, deve ser memorizado e reproduzido em avaliações futuras (MENDES; AMORIM, 2019).

O uso de ferramentas tecnológicas, associadas às metodologias ativas de aprendizagem colaborativa, possibilitam a troca de ideias entre os alunos, o que permite a construção do aprendizado coletivo e em equipe, de forma que as habilidades são desenvolvidas naturalmente, e o papel do professor é de gerenciamento (TAJRA, 2001 apud MENDES; AMORIM, 2019).

De acordo com Valente, Almeida e Geraldini (2017), as metodologias ativas são estratégias pedagógicas caracterizadas como ativas devido à aplicação de práticas pedagógicas para envolver os alunos, engajá-los em atividades práticas, em que são protagonistas da sua aprendizagem (VALENTE; ALMEIDA; GERALDINI, 2017).

Em especial, na metodologia da sala de aula invertida (SAI), utilizada nesta proposta, promove-se a inversão da sala de aula tradicional, oportunizando ao aluno o estudo e o acesso ao conteúdo antes da aula formal (OLIVEIRA; LIMA; PAIM, 2018).

O compartilhamento de conhecimento e experiência entre aqueles que produzem um texto cria uma peça abrangente de produto escrito (RASHID; YUNUS; WAHI, 2019). Isso reflete os aspectos socioculturais em que o conhecimento é bastante aprimorado em um contexto social (Vygotsky, 1978).

Segundo Walesko (2017), mitos relacionados ao ensino e aprendizagem de língua inglesa influenciam as práticas dos professores em sala de aula há bastante tempo. A Base Nacional Comum Curricular (BNCC) se fundamenta em dez competências gerais a serem desenvolvidas ao longo de todo o processo educacional. Os eixos principais a serem desenvolvidos em língua inglesa são oralidade, leitura, escrita, conhecimentos linguísticos e dimensão intercultural. Os conhecimentos linguísticos estão relacionados à análise e à reflexão sobre a língua, sempre de modo contextualizado e articulado (BRASIL, 2017). 
Walesko (2017) alerta para a relação que existe entre a globalização, o multilinguisimo e o ensino de línguas adicionais.

É importante estimular que os alunos usem variadas ferramentas no processo de aprendizagem de uma língua estrangeira, para motivar e colaborar com a prática da língua (CASTRO, 2019).

A pesquisa denominada "Project Tomorrow", nos Estados Unidos, constatou que 51\% dos professores de língua inglesa consideram o uso das tecnologias na sala de aula como facilitadoras do aprendizado dos alunos (ERTMER; LEFTWICH, 2010).

A aprendizagem dos alunos fora do contexto escolar é gerida por suas demandas pessoais, sejam elas para seu futuro, para sua inserção no meio virtual, para sua comunicação ou apenas porque gostam ou necessitam utilizar a língua inglesa (SOUZA et al., 2013). A crescente falta de motivação em se aprender inglês na escola está relacionada, segundo o autor, ao fato de o contexto escolar propiciar apenas uma manipulação meramente estrutural e instrumental da língua, sem um contexto social.

Como mediador e facilitador do processo de ensino e aprendizagem, o professor deve oferecer atividades e propostas educativas que se internalizem de maneira significativa aquilo que se ensina (BACICH; TANZI NETO, 2015). Ao incluir metodologias ativas, abrem-se caminhos para avançar mais no conhecimento profundo e em novas práticas (MORAN, 2015).

\section{METODOLOGIA}

O trabalho, de vertente qualitativa, envolveu 152 alunos dos $6^{\circ}$ e $7^{\circ}$ anos do Ensino Fundamental e foi realizado ao longo do primeiro semestre de 2020. A abordagem qualitativa se preocupa com aspectos da realidade que não podem ser quantificados, com foco na compreensão e explicação da dinâmica das relações sociais (GERHARDT; SILVEIRA, 2009, p. 32).

Ao todo, foram quatro práticas realizadas e avaliadas. O ambiente Padlet foi preparado com duas propostas para o $6^{\circ}$ ano e mais duas para o $7^{\circ}$ ano do Ensino Fundamental em seu segundo segmento, planejadas para introduzir novos conteúdos gramaticais e/ou novo vocabulário, sobre temas em consoante com os propostos pela BNCC de cada série. Com estas propostas, visou-se contribuir para a ampliação das possibilidades no estudo da língua inglesa e motivar os alunos a resolver as atividades também fora do contexto da sala de aula, além deles estarem no centro do processo de aprendizagem e de aprenderem ao observar as contribuições dos colegas e socializar as suas.

A primeira proposta do $6^{\circ}$ ano versava sobre as carreiras que os alunos pretendiam seguir no futuro e foi encaminhada às turmas antes de abordar o tema "Professions" com as turmas. Após uma pesquisa sobre a carreira em questão, o estudante criava uma fotomontagem dele mesmo no cenário da carreira escolhida e compartilhava no mural, junto à justificativa de ter escolhido aquela profissão. Cada aluno postava as respostas no Padlet de sua turma e, para tanto, utilizava para descrição o tempo verbal Simple Present Tense. Num segundo momento, a professora trabalhou o vocabulário sobre profissões com as turmas (Figura 1).

No segundo Padlet desta série, os alunos pesquisaram sobre feriados mundiais. E cada aluno escolheu um feriado diferente para contar sua história, sua origem e datas. Era 
imperativo que os feriados não se repetissem, o que demandou uma pesquisa maior e proporcionou mais acréscimo ao vocabulário dos alunos. Essa atividade foi desenvolvida como primeira abordagem ao tema "Holidays", explicado em seguida pela professora na aula on-line.

No $7^{\circ}$ ano, a primeira proposta consistia em, inicialmente, descrever suas percepções do período de quarentena, comentando a nova rotina e as atividades realizadas. Para tanto, os alunos utilizaram os tempos verbais Simple Present Tense e Present Continuous Tense, e a diferença entre os usos e estruturas dos dois tempos verbais foram elucidadas na aula síncrona, logo após a atividade no Padlet ser concluída.

No segundo mural, o alunos do $7^{\circ}$ ano escreveram sobre uma viagem memorável de cada um. Para tanto, eles utilizaram o tempo verbal Simple Past Tense e adicionaram fotos pessoais ao seu relato. A abordagem gramatical do conteúdo e vocabulário de viagens foram sistematizados, no encontro on-line seguinte, pela professora com os alunos (Figura 2).

Figura 1 - Atividade do $6^{\circ}$ ano no Padlet "My Future Career".

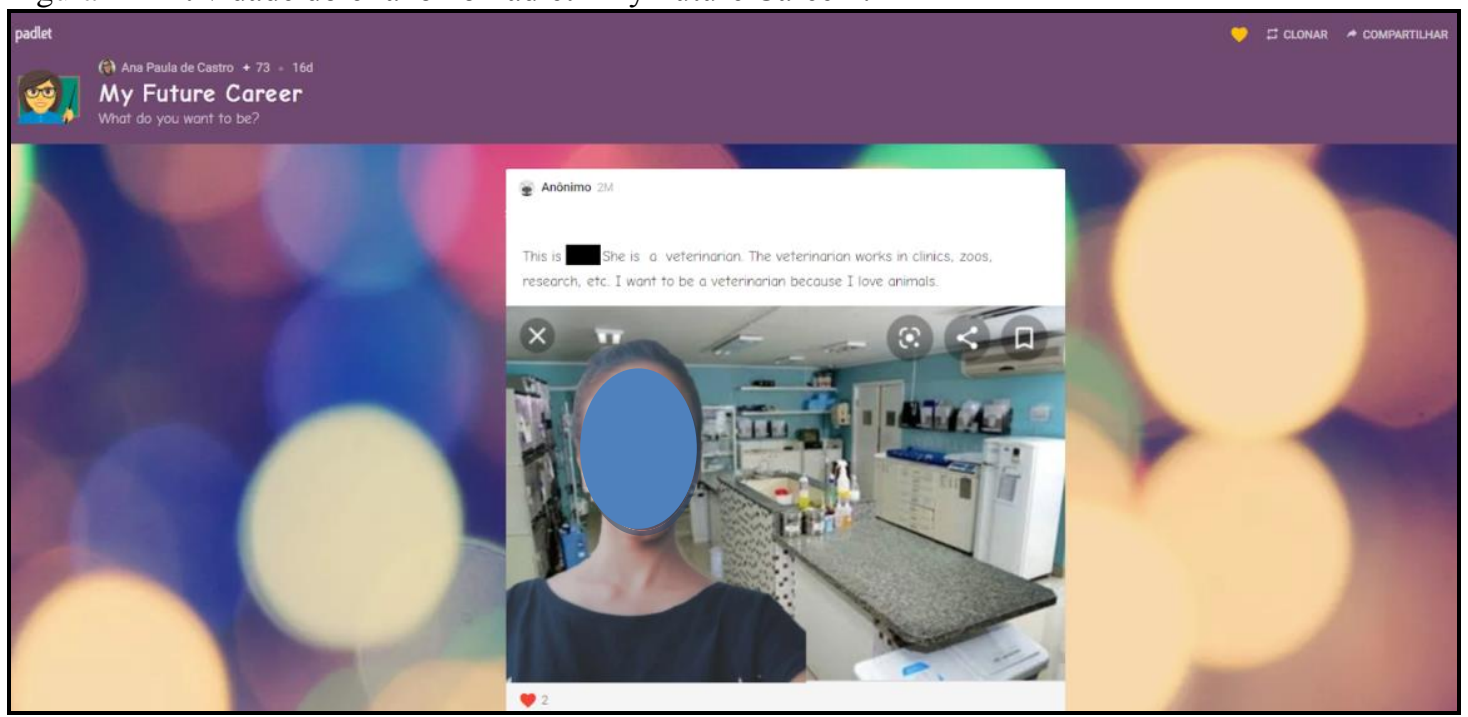

Fonte: https://padlet.com/apaulacastro76/myfuturecareer - Elaboração própria. 
Figura 2 - Atividade do $7^{\circ}$ ano no Padlet "Traveling Review".

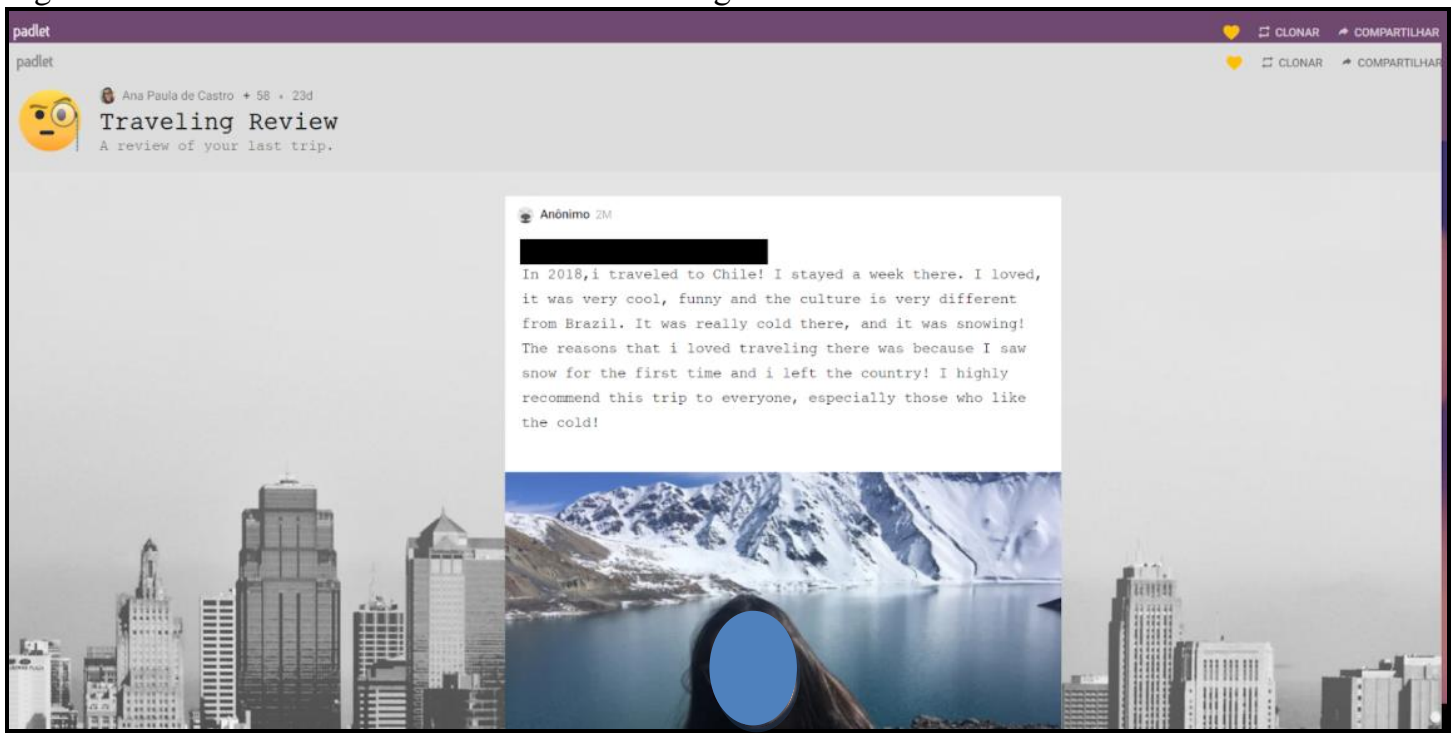

Fonte: https://padlet.com/apaulacastro76/vacations - Elaboração própria.

Portanto, em todas as práticas no Padlet, foi utilizada a metodologia ativa Flipped Classroom ou Sala de Aula Invertida (SAI), que consiste em uma estratégia de inversão da lógica organizacional dos acontecimentos em um processo de ensino aprendizagem tradicional. Antes da aula presencial, os alunos entram em contato com o conteúdo da aula para que possam estudá-lo por meio de mídias digitais. $\mathrm{Na}$ aula em si, o assunto e o tempo são abordados de forma dinâmica e interativa (MENDES; AMORIM, 2019).

Como complementam Mendes e Amorim (2019), essa metodologia consiste em uma metodologia ativa e colaborativa, em que a proposta é centrada no aluno e não mais no professor. Este "passa a ser um facilitador de aprendizagem, guiando o estudo e gerenciando as atividades da equipe de aprendizagem" (MENDES; AMORIM, 2019, p.648).

Após a realização destas práticas, a coleta de dados foi realizada por meio de observação, análise documental (das atividades dos alunos) e questionário semiestruturado aplicado aos sujeitos da pesquisa. Dos 152 alunos envolvidos, 123 responderam ao questionário.

\section{RESULTADOS E DISCUSSÃO}

Como já mencionado, 152 alunos de $6^{\circ}$ e $7^{\circ}$ anos do Ensino Fundamental II participaram das atividades propostas no Padlet. Para acessar as atividades, os alunos receberam um link que concedia o acesso a cada mural.

A primeira atividade do $6^{\circ}$ ano foi realizada de 30 de março a 04 de abril de 2020 . Os alunos conseguiram realizar a atividade com facilidade, mesmo tendo sido a primeira vez que alguns deles acessaram a ferramenta, e demonstraram satisfação em fazê-la. Após a pesquisa, os alunos postaram seus desejos sobre suas profissões futuras e justificaram suas escolhas. 
"This is (Aluno 1). He wants to be a doctor because they help sick people to recover their health and they are true angels! Doctors works at hospitals and medical centers and they work a lot! Medicine is a profession that fascinates me! I always wanted to work to help others and this is the best way! It is wonderful to know that I have been able to contribute to someone's health. That's my mission on Earth" (Aluno 1).

Foi interessante verificar que, à medida que novas postagens surgiam, as descrições se tornavam mais detalhadas e as montagens mais criativas. Muitos alunos afirmaram que ver a atividade dos colegas antes, exposta no mural Padlet, contribuiu na realização da própria escrita pessoal, "pois quando você observa a dos seus colegas, a pessoa consegue ter uma ideia do que fazer, qual modelo devemos seguir" (Aluno 11). Entretanto, 13,5 \% dos alunos relataram que não se inspiraram nas outras publicações.

A colaboração é identificada como um dos elementos-chave na comunicação eficaz, essencial para o desenvolvimento das habilidades do século XXI (RASHID; YUNUS; WAHI, 2019). De acordo com Greenstein (2012), colaboração eficaz ocorre ao aprender a planejar e trabalhar em conjunto, a considerar perspectivas diversas e participar do discurso, contribuindo, ouvindo e apoiando os outros (GREENSTEIN, 2012).

Na segunda tarefa, realizada no período de 29/06 a 07/07, os alunos do $6^{\circ}$ ano pesquisaram sobre feriados e publicaram suas escolhas no mural "Holidays around the world". A adesão ao segundo mural foi muito mais contagiante, tendo em vista a experiência que os alunos já haviam adquirido com a ferramenta e porque gerou uma curiosidade maior em torno da cultura de diferentes países. Todos os alunos concluíram a atividade antes do prazo final estabelecido e comentaram, nas aulas subsequentes, sobre aspectos culturais e vocabulário absorvido por meio das publicações compartilhadas.

No $7^{\circ}$ ano, a realização do primeiro Padlet - "My personal blog" - foi um pouco mais tímida, e muitos atribuíram este fato ao início da quarentena e do isolamento social atribuído ao advento da Covid-19. O mural foi proposto em 28/03. Porém, com base nas observações em aula, muitos apreciaram a oportunidade de compartilhar seus sentimentos em relação à nova rotina. E puderam praticar a língua inglesa, que estava sem uso rotineiro naquele momento.

O segundo mural do $7^{\circ}$ ano, "Traveling Review", realizado entre 25/05 e 01/06, foi realizado com entusiasmo pelos alunos e, da mesma forma em que ocorreu com o $6^{\circ}$ ano, as publicações foram se tornando mais elaboradas à medida que os alunos inspiravam-se nos posts dos colegas anteriores.

Após a conclusão das postagens, os alunos 123 alunos, dos 152 envolvidos na pesquisa, responderam ao questionário acerca das percepções sobre as atividades e sobre o Padlet. É importante verificar que $86 \%$ dos alunos entrevistados não conheciam a ferramenta antes da utilização nas atividades de língua inglesa.

Ao serem questionados se encontraram dificuldade na realização das atividades no Padlet, 76,4\% dos alunos afirmaram que não, sendo que 57,5\% deles utilizaram o celular para realizar as atividades (Gráfico 1). 
IX Congresso Brasileiro de Informática na Educação (CBIE 2020)

Anais do XXVI Workshop de Informática na Escola (WIE 2020)

Gráfico 1 - Se o aluno teve dificuldade em realizar as atividades no Padlet.

Você teve dificuldade na realização das atividades no padlet?

127 respostas

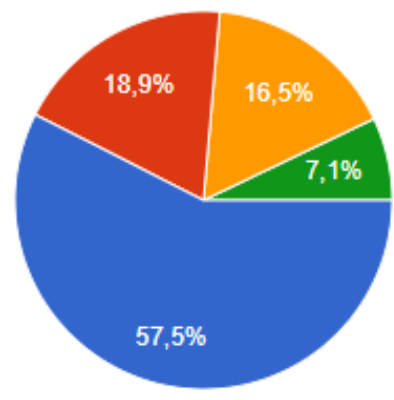

Não. Usei meu celular para realizar

Não. Usei o computador para realizar.

Sim, tive dificuldade e precisei da ajuda de um adulto.

Sim, mesmo com ajuda, não consegui fazer.

Fonte: elaboração própria.

Dos 123 alunos, 95\% deles acreditam que a realização de atividades de Língua Inglesa no Padlet contribui para a aprendizagem da escrita em Inglês e apenas seis deles declararam que não fez diferença a utilização do Padlet em comparação com as atividades mais tradicionais.

O Aluno 31 declarou que, "no Padlet, nós precisamos muitas vezes usar palavras que não conhecemos e, desse modo, nós treinamos a escrita" (Aluno 31). Em consoante, o Aluno 4 declarou que "além de eu conseguir colocar a minha resposta, eu também conseguia ver as dos meus amigos, o que ajudava ainda mais a aprender" (Aluno 4).

Por fim, ao serem indagados se o uso do Padlet deixa as atividades de aula e/ou casa mais interessantes, $98 \%$ deles afirmaram que sim. Apenas um aluno disse que se sentia mais confortável com a realização de quizzes e dois se abstiveram de responder. $\mathrm{O}$ Aluno 118 escreveu que "o Padlet é muito legal, tipo uma rede social, podemos ver nossas publicações e dos nossos amigos" (Aluno 118).

Uma pesquisa semelhante sobre Padlet com um curso de comunicação também destacou que a ferramenta melhora o relacionamento professor-aluno, aumenta a motivação e a autoestima e pode proporcionar aos professores um modo alternativo de se comunicar com os alunos fora da sala de aula (RASHID; YUNUS; WAHI, 2019).

Nessa perspectiva, é necessário ajudar os jovens a crescerem como pensadores criativos e as novas tecnologias de informação e comunicação podem contribuir muito na implementação de ambientes de Aprendizagem Criativa (AC), promovendo uma postura ativa dos estudantes, não como consumidores da informação, mas como seus próprios criadores (GUARDA; SANTOS; GONÇALVES, 2019).

Diante disso, vê-se a necessidade de formação do corpo docente para a utilização destas práticas mais ativas, em que haja um domínio do papel de mediador que o professor assume (SANTOS, 2019).

\section{CONCLUSÃO}

Com base nas respostas obtidas no questionário, nas tarefas postadas pelos alunos e nas observações realizadas durante as aulas, percebe-se que a habilidade escrita em língua 
inglesa pode ser aprimorada com a colaboração entre os alunos, por meio da ferramenta on-line interativa Padlet.

O uso da plataforma Padlet, associada à metodologia ativa SAI, foi bem aceita pelos alunos e que o uso da ferramenta em forma de mural contribuiu como um fator de auxílio à criatividade, à escrita e à aprendizagem do vocabulário.

Também foi possível perceber que o Padlet propiciou um ambiente de controle adequado para o professor gerenciar o ritmo de aprendizagem da turma. Em tempo, ressalta-se que a metodologia e a plataforma adotadas precisam ser bem apresentadas aos alunos, já que a aplicação das mesmas com eficiência depende do entendimento acerca de sua utilização, além de um entrosamento e envolvimento por parte da turma.

Espera-se que esse artigo possa contribuir na discussão sobre uso de metodologias ativas aliadas a ferramentas tecnológicas, potencializando o processo de aprendizagem. A inclusão de TDIC na prática do educador permite que os professores assumam o papel de facilitadores e liderem alunos para que eles se tornem aprendizes autônomos e mais motivados.

\section{REFERÊNCIAS:}

BACICH, L.; TANZI NETO, A.; TREVISANI, F. Ensino híbrido: personalização e tecnologia na educação. Porto Alegre: Penso Editora, 2015.

BRASIL. Ministério da Educação. Base Nacional Comum Curricular. 2017. Disponível em: http://basenacionalcomum.mec.gov.br/abase. Acesso em: 17 jul. 2020.

CASTRO, A. P. Ensino Híbrido no Estudo de Inglês no Centro de Línguas: um Caminho em Construção na Educação Profissional e Tecnológica. Dissertação (Mestrado em Ensino Profissional e Tecnológico) - Instituto Federal Fluminense, IFF, Campos dos Goytacazes, RJ, 2019.

ERTMER, P. LEFTWICH, A. Teacher technology change: How knowledge, confidence, beliefs, and culture intersect. Journal of Research on Technology in Education v. 42, n. 3, p. 255-284. 2010. Disponível em https://www.tandfonline.com/doi/abs/10.1080/15391523.2010.10782551. Acesso em: 20 jun. 2018.

GERHARDT, T. E; SILVEIRA, D. T. Métodos de Pesquisa. Série Educação a Distância. Coordenado pela Universidade Aberta do Brasil - UAB/UFRGS e pelo Curso de Graduação Tecnológica - Planejamento e Gestão para o Desenvolvimento Rural da SEAD/UFRGS. Porto Alegre. 2009.

GREENSTEIN, L. M. Assessing 21st Century Skills: A Guide to Evaluating Mastery and Authentic Learning . Ed. Sage Publications. Corwin Press. Califórnia. The USA. 2012.

GUARDA, G. F., CUNHA, L. R. R., GONÇALVES, C. S. Uso de Aplicativos Educacionais - Experiências com Aprendizagem Criativa na Educação Básica. In: VIII Congresso Brasileiro de Informática na Educação (CBIE 2019). Anais [...]. Brasília: 2019. p. 138-147. Disponível em: $\underline{\text { https://br- }}$ ie.org/pub/index.php/wie/article/view/8500. Acesso em: 17 jul. 2020. 
MENDES, L. F., AMORIM, N. O., Uso da plataforma web Google Classroom como ferramenta de apoio à metodologia Flipped Classroom: relato de aplicação no curso de Bacharelado em Sistemas de Informação. In: VIII Congresso Brasileiro de Informática na Educação (CBIE 2019). Anais [...]. Brasília: 2019. p. 138-147. Disponível em: https://br-ie.org/pub/index.php/wie/article/view/8560. Acesso em: 17 jul. 2020.

MORAN, J. Novas tecnologias e mediação pedagógica. $6^{\text {a }}$ ed. Campinas: Papirus, 2015.

OLIVEIRA, M. A. F. LIMA, J. V. PAIM, G. R. Avaliações formativas coordenadas por estratégias de participação inspiradas na abordagem de ensino híbrido. In: VIII Congresso Brasileiro de Informática na Educação (CBIE 2019). Anais [...]. Brasília: 2019. p. 138-147. Disponível em: https://brie.org/pub/index.php/wie/issue/view/186. Acesso em: 24 set. 2020.

RASHID, A. A., YUNUS, M. M., \& WAHI, W. Using Padlet for Collaborative Writing among ESL Learners. Creative Education, v.10, p. 610-620. 2019. Disponível em: https://doi.org/10.4236/ce.2019.103044. Acesso em: 17 jul. 2020.

SANTOS, S. F. Um Caminho Teórico Percorrido Ativamente: Ensino Híbrido na Disciplina Teorias de Aprendizagem - Uma Experiência Inovadora no Curso de Pedagogia. Dissertação (Mestrado em Ensino e sua Tecnologias) - Instituto Federal Fluminense, IFF, Campos dos Goytacazes, RJ, 2019.

SOUZA, M. V. et al. Mídias Sociais, AVAs e MOOCs: Reflexões Sobre Educação em Rede. In: International Conference On Interactive Computer Aided Blended Learning. Araranguá . Anais [...] Araranguá: UFSC. p. 1-8. Disponível em: http://www.labmidiaeconhecimento.ufsc.br/files/2014/11/Contribution62_a.pdf. Acesso em: 17 jul. 2020.

VALENTE, J. A.; ALMEIDA, M. E. B.; GERALDINI, A. F. S. Metodologias ativas: das concepções às práticas em distintos níveis de ensino. Revista Diálogo Educacional, v. 17, n. 52. p. 455- 478. São Paulo: 2017.

VYGOTSKY, L.S. Mind in Society: the development of higher mental processes. Cambridge, Harvard University Press. 1978.

WALESCO, A. Formação Inicial e o Mito do "Falante Nativo": Construções Identitárias de Professores de Inglês em uma Comunidade de Prática. Tese (Doutorado em Letras) - Universidade Federal do Paraná. Curitiba, Paraná. 2019. 